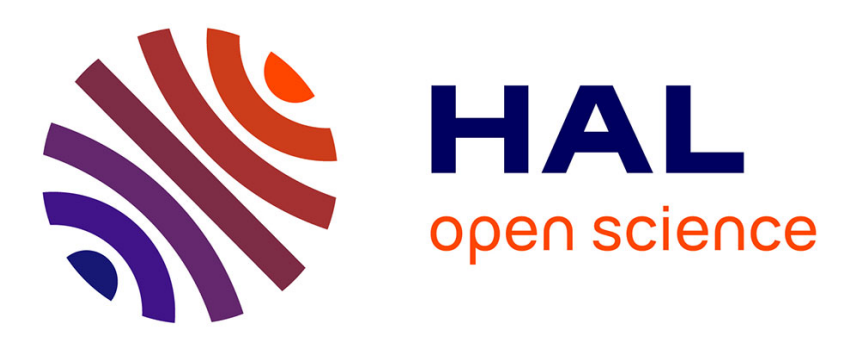

\title{
Simulation of Substructure Evolution During High-Speed Deformation
}

\author{
W. Pantleon, J. Trotzschel, P. Klimanek
}

\section{To cite this version:}

W. Pantleon, J. Trotzschel, P. Klimanek. Simulation of Substructure Evolution During HighSpeed Deformation. Journal de Physique IV Proceedings, 1997, 07 (C3), pp.C3-649-C3-654. 10.1051/jp4:19973111 . jpa-00255396

\section{HAL Id: jpa-00255396 https://hal.science/jpa-00255396}

Submitted on 1 Jan 1997

HAL is a multi-disciplinary open access archive for the deposit and dissemination of scientific research documents, whether they are published or not. The documents may come from teaching and research institutions in France or abroad, or from public or private research centers.
L'archive ouverte pluridisciplinaire HAL, est destinée au dépôt et à la diffusion de documents scientifiques de niveau recherche, publiés ou non, émanant des établissements d'enseignement et de recherche français ou étrangers, des laboratoires publics ou privés. 


\title{
Simulation of Substructure Evolution During High-Speed Deformation
}

\author{
W. Pantleon, J.T.R. Trotzschel and P. Klimanek \\ Freiberg University of Mining and Technology, Institute of Physical Metallugy, Gustav-Zenner str. 5, \\ 09596 Freiberg, Germany
}

\begin{abstract}
A model for the evolution of the substructure during high-speed deformation is proposed taking into account all relevant defects in a dislocation structure: trapping of dislocations in dislocation walls, annihilation after cross slip of screw dislocations and vacancy-assisted climb of edge dislocations. The evolution equations for the defect densities as well as for the temperature are implemented in the finite element code LS-DYNA3D. Simulations of hot-compression of aluminium single crystals with a ballistic plastometer are compared with experimental results.

Résumé. Un modèle pour l'évolution d'une sous-structure pendant la déformation à grande vitesse est proposé tenant en compte de tous les défauts apparaissant dans une structure de dislocations: insertion des dislocations dans des murs de dislocations, annihilation des dislocations vis après glissement dévié et montée des dislocations coin à l'aide des lacunes. Les équations d'évolution de la densité de ces défauts ainsi que celles de la température ont été exprimées en utilisant la méthode des éléments finies en code de LS - DYNA3D. Les résultats des simulations d'une compression à haute température des monocristaux d'Aluminium réalisée avec un plastomètre balistique et les résultats expérimentaux ont été comparés.
\end{abstract}

\section{INTRODUCTION}

High-speed deformation of metals leads to serious effects on the evolution of the substructure. Not only the temperature rise caused by nearly adiabatic conditions has a significant influence on the substructure, but also the processes of dynamic softening are strongly affected by the high imposed strain rates and the short duration of the deformation (e.g. [1]). Additionally, the impact characteristic of the dynamic loading may influence the homogeneity of the distribution of plastic strain during the deformation process (cp. [2]). Based on a model for the evolution of the substructure these effects are studied here in some detail by a simulation of the compression test with a ballistic plastometer.

\section{EXPERIMENTAL DETAILS}

Compression tests with high strain rates are carried out using the ballistic plastometer at the Freiberg University of Mining and Technology. With this device the impact of a projectile accelerated by gaspressure release is transmitted through an intermediate piece on a punch which upsets the specimen sitting on top of an output bar $[2,3]$. The recorded displacement of the upper end of the punch reflects the compression of the specimen. Strain gages at the output bar determine the transmitted force applied on the sample under consideration. The specimen as well as part of the punch are surrounded by a heat-container allowing deformation at elevated temperatures.

With this experimental tool cylindrical aluminium single crystals $\left(\varnothing 10 \times 15 \mathrm{~mm}^{3}\right)$ are compressed along the [001] axis at $335^{\circ} \mathrm{C}$. The initial projectile velocity of $47 \mathrm{~m} / \mathrm{s}$ leads to an initial velocity of $18 \mathrm{~m} / \mathrm{s}$ of the punch (fig. 1a). In fig. Ib it becomes obvious that the first detection of $a$ 
force in the output bar is delayed with respect to the onset of the movement of the punch which can be attributed to the time necessary for the propagation of the loading wave front through the punch: and the specimen. From the upsetting of the specimen the (logarithmic) strain $\epsilon$ in the specimen and (by differentiation) the imposed strain rate $\dot{\epsilon}$ can be calculated. Fig. 1c shows a continuous increase of the strain rates up to $\dot{\epsilon}=1600 \mathrm{~s}^{-1}$ at $\epsilon=0.8$.

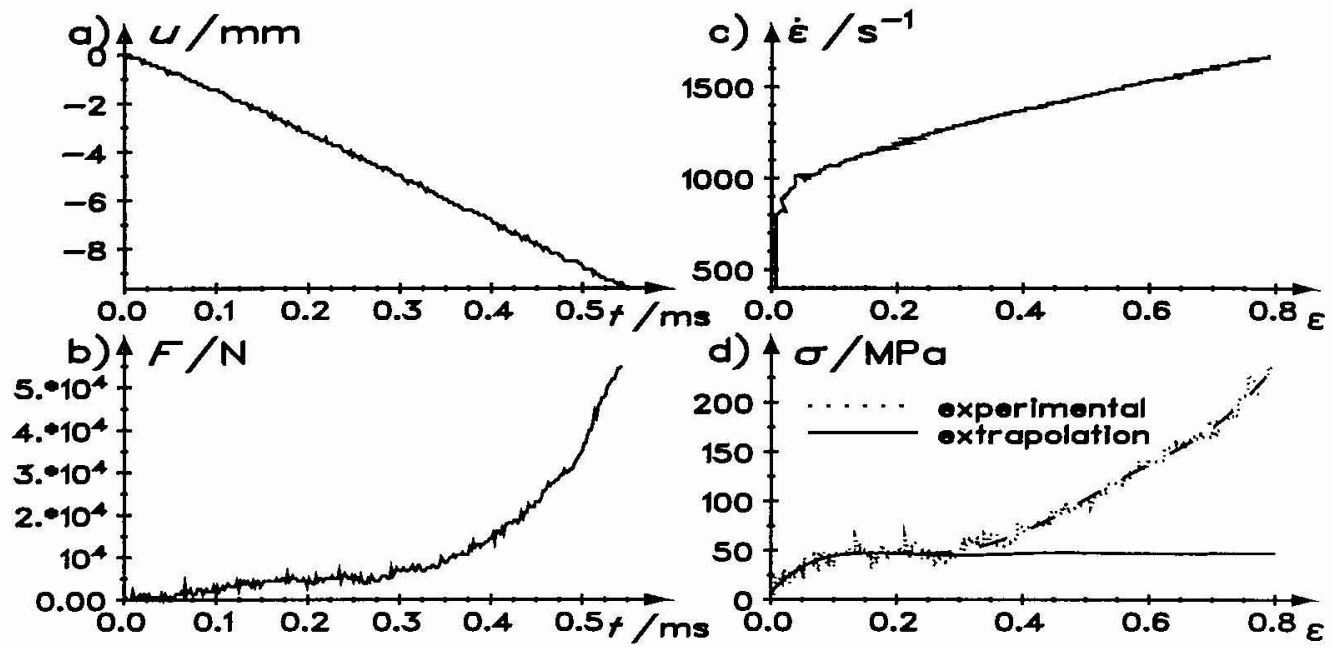

Figure 1: Compression of an aluminium single crystal with a ballistic plastometer (experimental data): a) displace. ment of the punch and b) transmitted force in dependence on time (the deformation is shown till $\epsilon=1.0$ only: $)$ strain rate and d) true stress in dependence on logarithmic strain.

Taking into account the time shift between the two signals the (true) applied stress $\sigma$ in the specimen can be established. The stress-strain curve in fig. 1d shows an initial hardening leading to a nearly constant value of the stress. From the linear decrease of the work hardening coefficient with stress the deformation up to $\epsilon=0.25$ can be identified as a stage III behaviour with a "stationary" stress $\sigma=47 \mathrm{MPa}$. Between $\epsilon=0.25$ and $\epsilon=0.75$ a strong and nearly linear increase of the applied stress $(\Theta=\mathrm{d} \sigma / \mathrm{d} \epsilon=350 \mathrm{MPa})$ occurs. At higher strains the stress starts to increase enormously. This strong increase is mainly caused by the three-axial stress state resulting form an enlarged influence of the friction due to the penny shape of the specimens after an upset of $10 \mathrm{~mm}$ and is, of course. not an effect of the material behaviour.

For several single crystals the deformation was interrupted after a certain strain and the samples were immediately quenched. TEM investigations of the center of a specimen deformed to $\epsilon=0.45$ confirm the appearance of dislocation cells. The dislocation structure has a mean FERET diameter of $2.3 \mu \mathrm{m}$ and neither significant inhomogeneities nor an obvious hierarchy of the dislocation boundaries arise. By EBSD a mean disorientation angle of $0.8^{\circ}$ is determined between adjacent cells. Additonal microhardness measurements on several samples deformed between $\epsilon=0.42$ and 0.70 show a nearly constant value $33 \mathrm{HV}_{0.002}$. Therefore, the flow stress contribution of the substructure of this samples should be similar and the strong increase of the flow stress in this region should be attributed to dynamic effects.

\section{MATERIALS MODEL}

\subsection{General}

The plastic deformation of the specimen is treated here with a material law which describes not only the dependence of the flow stress on the process parameters (strain rate $\dot{\epsilon}$ and temperature 
T) but also the effects of the resulting substructure - based on considerations about the evolution of structure variables $S$ as the dislocation density $\rho$ or the excess vacancy concentration $\Delta c$ in the sample. Therefore, not only the kinetic equation

$$
\dot{\epsilon}_{\mathrm{pl}}=f_{\mathrm{kin}}\left(S ; \sigma_{\mathrm{vM}}, T\right)
$$

for the dependence of the strain rate $\dot{\epsilon}$ on the applied equivalent (vON Mises) stress $\sigma_{\mathrm{vM}}$ becomes relevant, but also the evolution of the (sub)structure variables

$$
\frac{\mathrm{d} S}{\mathrm{~d} \dot{\epsilon}_{\mathrm{pl}}}=f_{S}\left(S ; \dot{\epsilon}_{\mathrm{pl}}, T\right)
$$

has to be specified. Furtherone, due to the plastic work $\delta w=\sigma_{\mathrm{vM}} \mathrm{d} \epsilon_{\mathrm{pl}}$ the internal energy of the system will be increased significantly $(\mathrm{d} u=\delta w+\delta q)$. For the high strain rates of interest the exchange of heat between the sample and the deformation tools is limited by the short deformation times and the process is treated adiabatically $(\delta q=0)$. Consequently, with respect to the energy stored in the substructure a temperature increase has to be taken into account [4]:

$$
\frac{\mathrm{d} T}{\mathrm{~d} \epsilon_{\mathrm{pl}}}=f_{T}\left(S ; \dot{\epsilon}_{\mathrm{pl}}, T\right)
$$

\subsection{Kinetics}

Determining the motion of mobile dislocations carrying the plastic flow the approach of SEEGER [5] is used. Only a certain amount of the applied vON Mises stress the effective stress $\sigma_{\text {eff }}=\sigma_{\mathrm{vM}}-\sigma_{\text {ath }}$ will lead to a certain velocity $v^{\mathrm{m}}$ of the mobile dislocation and consequently to a plastic strain rate $\dot{\epsilon}_{\mathrm{pl}}=m n b \rho^{\mathrm{m}} v^{\mathrm{m}}$. The athermal part of the flow stress is determined by the TAYLoR-relation $\sigma_{\text {ath }}=\alpha \mu b \sqrt{\rho} / m$, where the total dislocation density $\rho=\xi\left(\rho_{\mathrm{s}}+\rho_{\mathrm{e}}\right)$ is given by the dislocation densities in the walls and the volume fraction $\xi$ of them.

Two different regimes of the dislocation motion are considered (cp. $[7,8])$ : The thermal activated motion of dislocations overcoming boxshaped obstacles with a velocity $v^{\mathrm{m}}$ and a strain rate

$$
\dot{\epsilon}_{\mathrm{pl}}=\dot{\epsilon}_{\mathrm{pl}, 0} \exp \left(-\frac{\Delta G}{k_{\mathrm{B}} T}\right) \sinh \left(\frac{\Delta G}{k_{\mathrm{B}} T} \frac{\sigma_{\mathrm{eff}}}{\sigma_{\mathrm{eff}, 0}}\right)
$$

where $\dot{\epsilon}_{\mathrm{pl}, 0}=10^{7} \mathrm{~s}^{-1}, \Delta G=10.25 * 10^{-20} \mathrm{~J}$ and $\sigma_{\mathrm{eff}, 0}=270 \mathrm{MPa}$ for aluminium are taken from [6]. (The introduced adjusting parameters $p$ and $q$ for non-boxshaped obstacles are neglected here.) On the other hand, especially for high strain rates an overdamped motion

$$
v^{\mathrm{m}}=\frac{m b}{B} \sigma_{\mathrm{eff}} \quad \text { and } \quad \dot{\epsilon}=\frac{n m^{2} b^{2} \rho^{\mathrm{m}}}{B} \sigma_{\mathrm{eff}}=\frac{\sigma_{\mathrm{eff}}}{\beta}
$$

is frequently discussed in the literature (cp. $[7,8]$ ). Here, from the coefficient $B=10^{-5} \mathrm{Pas}$ for copper at room temperature [9] a "strain rate sensivity" $1 / \beta=3 * 10^{-5} \mathrm{Pas}$ at elevated temperature is estimated for aluminium.

\subsection{Substructure evolution}

In order to describe the evolution of the substructure the model of PANTLEON and KLIMANEK $[10,11]$ for the defect densities developed for the hot-working of f.c.c. single crystals in symmetrical polyslip is used here for aluminium. Assuming a dislocation cell structure the model describes not only the accumulation of dislocations in the cell walls due to the dislocation fluxes of mobile dislocations, but also mutual annihilation of dislocations of opposite sign of the BuRgers vector. Therefore, both dislocation characters are treated separately. Edge dislocations may annihilate only, if they pass a possible partner within a slip plane distance less then $y_{\mathrm{e}}=6 b$. Alternatively, they 
have to climb towards another before annihilation by the consumption of vacancies. Consequently: the production of vacancies caused by the plastic deformation (resp. the motion of jogs on screw dislocations) and their diffusion to the sinks has to be considered. Due to their ability of cross slip the possible annihilation length of screw dislocations $y_{\mathrm{s}, \mathrm{eff}}\left(\sigma_{\mathrm{ath}} ; \dot{\epsilon}_{\mathrm{pl}}, T\right)$ with a maximal value of $y_{\mathrm{s}, \text { eff } \max }=0.7 * 10^{-6} \mathrm{~m}$ will depend on the stress and temperature but also on the strain rate, because an increased strain rate will reduce the time for a mobile screw dislocation traversing a dislocation cell wall and, therefore, their chance of undergoing cross slip events.

A detailed description of the elementary processes leads to the following set of differential equations for the evolution of the plastically induced vacancy concentration $\left(\Delta c_{\mathrm{pl}}\right)$ and the scres $\left(\rho_{\mathrm{s}}\right)$ and the edge $\left(\rho_{\mathrm{e}}\right)$ dislocation densities in the cell walls $[10,11]$ :

$$
\begin{array}{rlrl}
\frac{\mathrm{d} \Delta c_{\mathrm{pl}}}{\mathrm{d} \epsilon_{\mathrm{pl}}} & =\frac{2 b}{3 P m n} w \rho_{\mathrm{s}} & -\frac{24 D_{\mathrm{SD}}}{\dot{\epsilon}_{\mathrm{pl}} d^{2}} \frac{\Delta c_{\mathrm{pl}}}{c_{\mathrm{th}}} \\
\frac{\mathrm{d} \rho_{\mathrm{s}}}{\mathrm{d} \epsilon_{\mathrm{pl}}}=\frac{2}{b m n} \frac{P}{w}-\frac{2}{b m n} y_{\mathrm{s}, \mathrm{eff}}\left(\sigma_{\mathrm{ath}} ; \dot{\epsilon}_{\mathrm{pl}}, T\right) \rho_{\mathrm{s}} & \\
\frac{\mathrm{d} \rho_{\mathrm{e}}}{\mathrm{d} \epsilon_{\mathrm{pl}}}=\frac{2}{b m n} \frac{P}{w}-\frac{2}{b m n} y_{\mathrm{e}} \rho_{\mathrm{e}}-\frac{24 D_{\mathrm{SD}}}{\dot{\epsilon}_{\mathrm{pl}} d^{2}} \frac{\Delta c_{\mathrm{pl}}}{c_{\mathrm{th}}} \frac{d}{\sqrt{2} b} \rho_{\mathrm{e}} .
\end{array}
$$

\subsection{Temperature evolution}

The internal energy density $u$ of the specimen consists of a thermal contribution $u_{\mathrm{th}}=\rho^{*} c_{\mathrm{V}} T$ and a contribution $u_{\text {st }}$ related to the substructure. The dependence of the second part

$$
\mathrm{d} u_{\mathrm{st}}=\frac{\partial u_{\mathrm{st}}}{\partial \rho} \mathrm{d} \rho+\frac{\partial u_{\mathrm{st}}}{\partial \Delta c_{\mathrm{pl}}} \mathrm{d} \Delta c_{\mathrm{pl}}=\frac{\mu b^{2}}{4 \pi} \frac{1-\frac{\nu}{2}}{1-\nu} \ln \frac{1}{\sqrt{\rho} b} \mathrm{~d} \rho+\Delta H_{\mathrm{va}, \mathrm{f}} N_{\mathrm{at}} \mathrm{d} \Delta c_{\mathrm{pl}}
$$

on the defect densities is given by the elastic strain field of the dislocations and in case of the vacancies from their formation enthalpy $\Delta H_{\mathrm{va}, \mathrm{f}}$. Consequently, the temperature evolution can be determined from

$$
\frac{\mathrm{d} T}{\mathrm{~d} \epsilon_{\mathrm{pl}}}=\frac{1}{\rho^{*} c_{\mathrm{V}}}\left(\sigma-\frac{\mathrm{d} u_{\mathrm{st}}}{\mathrm{d} \epsilon_{\mathrm{pl}}}\right)=\frac{\sigma\left(S ; \dot{\epsilon}_{\mathrm{pl}}, T\right)}{\rho^{*} c_{\mathrm{V}}} \eta\left(S ; \dot{\epsilon}_{\mathrm{pl}}, T\right)
$$

with a 'degree of effectiveness' $\eta\left(S ; \dot{\epsilon}_{\mathrm{pl}}, T\right)$ depending on substructure and the deformation parameters [4].

\section{SIMULATION}

\subsection{Finite Element Simulation}

The commercial finite element code LS-DYNA3D used for the simulations is based on an explicite time integration scheme and all geometric nonlinearities are completely taken into account. In order to describe the compression with a ballistic plastometer a finite element mesh using one point integrated brick elements is designed consisting not only of the specimen but of all other relevant parts also, which are treated elastically. Symmetric contacts with Coulomb friction between the parts are established. Assuming an elastic behaviour of the specimen in a previous work [2] the correct description of propagating elastic waves through the entire system was demonstrated, if a proper time increment $\Delta t$ is chosen.

\subsection{Implementation of the materials law}

Based on the expressions of the previous section for the substructure evolution the plastic behaviou: of the aluminium single crystal specimens is implemented as a user-defined material law in the $\mathrm{FE}$ code. For each time step the amount of plastic deformation and the evolution of the state (history) 
variables $\left(\Delta c_{\mathrm{pl}}, \rho_{\mathrm{s}}, \rho_{\mathrm{e}}\right)$ describing the evolution of the substructure and the temperature $T$ has to be determined independently for each finite element: From the actual incremental strain tensor $\Delta \epsilon$ and the stress tensor $\boldsymbol{\sigma}$ of the previous time step a trial stress tensor and the vON MisEs equivalent stress $\sigma_{\mathrm{vM}}$ is calculated in each element. From the effective stress $\sigma_{\text {eff }}=\sigma_{\mathrm{vM}}-\sigma_{\text {ath }}(\rho)$ the plastic strain rate $\dot{\epsilon}_{\text {pl }}$ can be determined using one of the kinetic equations (4) or (5). This allows the separation of the plastic strain increment [12]

$$
\Delta \epsilon_{\mathrm{pl}}=\frac{3 \dot{\epsilon}_{\mathrm{pl}} \Delta t}{2 \sigma_{\mathrm{vM}}} \sigma^{\mathrm{dev}}
$$

and the integration of the evolution equations to update the set of history-variables for the specific element. Finally, the revised stress tensor $\sigma$ and the accumulated plastic strain tensor is returned to the main program.
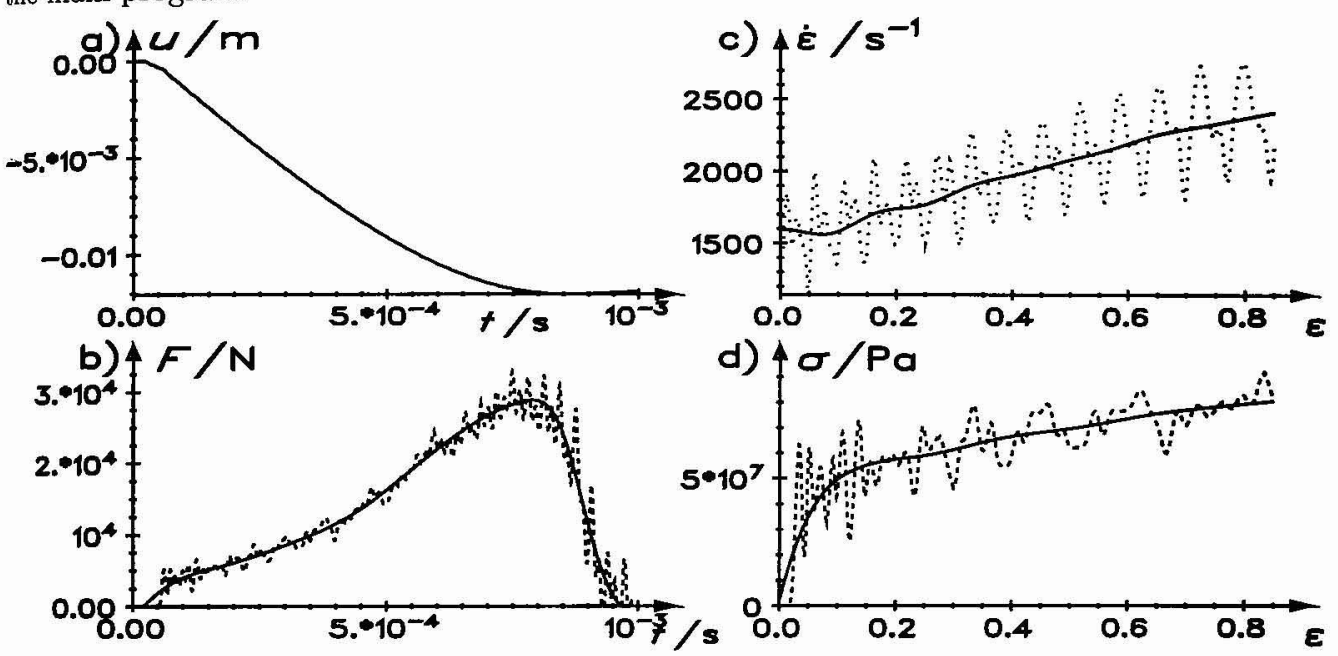

Figure 2: Simulation (with thermal activated dislocation motion) of the compression of an aluminium single crystal with a ballistic plastometer: a) punch displacement and b) transmitted force in dependence on time (up to $t=1 \mathrm{~ms}$ ), c) strain rate and d) true stress in dependence on logarithmic strain (dashed lines: simulation results, full lines: interpolating splines).

\subsection{Results}

For the same conditions as used in the experiments (projectile velocity $47 \mathrm{~m} / \mathrm{s}$ and a specimen temperature of $335^{\circ} \mathrm{C}$ ) the compression tests with the ballistic plastometer are simulated assuming either a thermal activated dislocation motion or an overdamped dislocation drag. Both simulations show large similarities and, therefore, only the results for thermal activation will be discussed further.

From fig. 2 it becomes obvious that indeed the first detection of a force in the output bar (fig. $2 \mathrm{~b}$, dashed line) is delayed with respect to the displacement of the punch (fig. 2a). At $t_{\text {end }}=0.85 \mathrm{~ms}$ the punch starts to move backward marking the end of the deformation process at a strain of $\epsilon=1.2$. The strain rate (fig. 2c) and the stress (fig. $2 \mathrm{~d}$ ) increase both monotonousely up to $\epsilon=1.0$. These features are in overall agreement with the experimental data, but there is no evidence for a plateau in the stress strain curve as obtained form the experiment (fig. 1d). Secondly, the punch velocity $(21 \mathrm{~m} / \mathrm{s})$ is higher in the simulation as measured in the experiment. This is mainly due to the ideal elastic behaviour of all moving parts of the plastometer and the idealized contact conditions in the simulation and is also reflected in the prediction of higher strain rates as experimentally observed.

As an example for the (time) evolution of the substructure the behaviour of the screw dislocations in the wall is summarized for several elements at different positions in the sample. The slight differences between the evolutions are mainly caused by small differences in the plastic strain within the specimen. After an initial overshooting $\left(1.2 * 10^{13} \mathrm{~m}^{-2}\right)$ due to the higher stress level and the enhanced cross slip the screw dislocations are enabled to annihilate mutually lowering the density 
to $8 * 10^{12} \mathrm{~m}^{-2}$. But this behaviour has only minor effects on the whole deformation process due to the small fraction of screw dislocations (Remarkably, the fraction of screws on the total dislocation content is higher than in simulations for low strain rates, in agreement with investigations [1].). all! other state variables reach their final values in a monotonous way: The temperature increase rises to

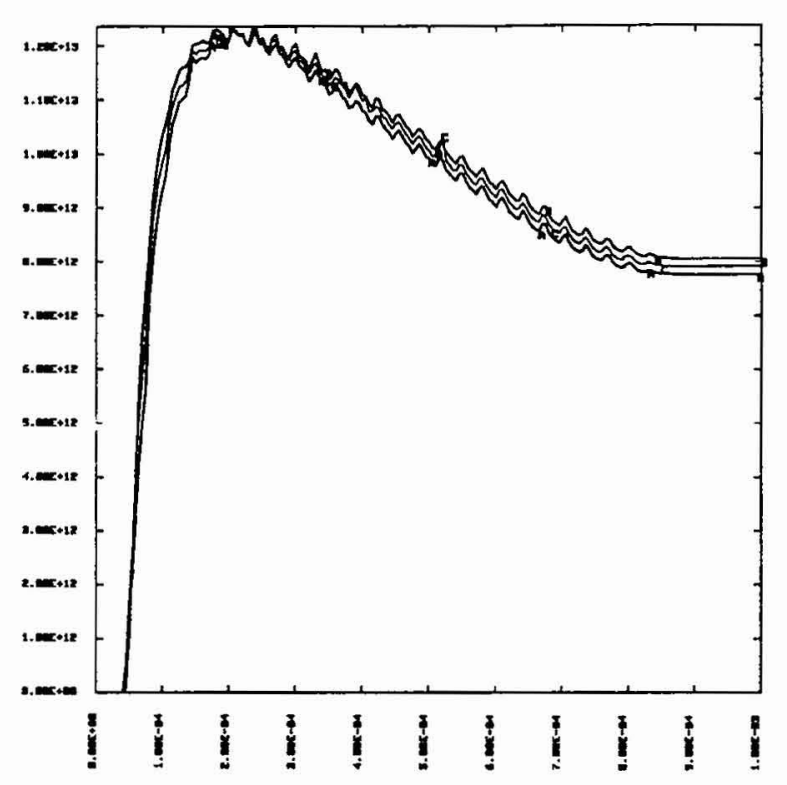

Figure 3: Evolution of the screw dislocation density $\rho_{\mathrm{S}}$ in the cell walls with deformation time $t$ for several elements during compression with a ballistic plastometer.
$T_{\text {end }} \approx 95 \mathrm{~K}$. E.g. at $t_{\text {end }}$ the vacancy concentration is $\Delta c_{\mathrm{pl}, \text { end }} \approx 8 * 10^{-4}$ or the edge dislocation density $1.2 * 10^{1.5} \mathrm{~m}^{-2}$, which clearly dominates the athermal part of the flow stress.

\section{Summary}

The compression test using a ballistic plastometer is simulated with an explicite finite element code taking into account all relevant parts of the experimental tool. Based on a model for the evolution of the substructure and the temperature simulations of the deformation of aluminium single crystals are in reasonable agreement with experimentally obtained data.

\section{Acknowledgement}

The authors gratefully acknowledge the financial support of the VolkswagenStiftung.

\section{References}

[1] Edington J.W., Phil. Mag. 19 (1969) 1189-1206.

[2] Trötzschel J., Pantleon W., Klimanek P., Comput. Mater. Sci. 7 (1996) 16-20.

[3] Ostwaldt D., Pantleon W., Klimanek P., Mat.-wiss. u. Werkstofftech. 27 (1996) 417-425.

[4] Pantleon W., Francke D., Klimanek P., Comput. Mater. Sci. 7 (1996) 75-81.

[5] Seeger A., Phil. Mag. 45 (1954) 771-773.

[6] El-Magd E. Dackweiler G., Hellwig K., Paffrath W., Mat.-wiss. u. Werkstofftech. 20 (1989) 42-47.

[7] Meyers M. A., Dynamic Behaviour of Materials, (John Wiley \& Sons, New York, 1994).

[8] El-Magd E., J. de Physique IV (1994) C8-149-170.

[9] Neuhäuser H., "Dynamical Effects in Deformation", Intern. Conf. on Strength of Metals and Alloys, Aachen 1979, P. Haasen et al. Eds. (Pergamon Press, Toronto 1980) Vol.3 pp. 1531 1550.

[10] Pantleon W., Klimanek P., "Modelling the initiation of DRX in Single Crystals by dislocation dynamics", 16th Risø Symposium on Materials Science, Roskilde 1995, N. Hansen et al. Eds. (Ris $\emptyset$ National Laboratory, Roskilde, Denmark 1995) pp. 473-478.

[11] Pantleon W., Modellierung der Substrukturentwicklung bei Warmumformung, Freiberger Forschungshefte B280 (TU Bergakademie Freiberg, 1996).

[12] Hill R., The Mathematical Theory of Plasticity (Clarendon Press, Oxford, 1950) pp. 14-69. 